EXTENDED REPORT

\title{
Three month treatment of reactive arthritis with azithromycin: a EULAR double blind, placebo controlled study
}

\author{
T K Kvien, J S H Gaston, T Bardin, I Butrimiene, B A C Dijkmans, M Leirisalo-Repo, P Solakov, \\ M Altwegg, P Mowinckel, P-A Plan, T Vischer
}

Ann Rheum Dis 2004;63:1113-1119. doi: 10.1136/ard.2003.010710

\begin{abstract}
See end of article for authors' affiliations

Correspondence to:

Professor T K Kvien,

Department of

Rheumatology,

Diakonhiemmet Hospital

Box 23 Vinderen, $\mathrm{N}-0319$

Oslo, Norway; t.k.kvien@

medisin.vio.no
\end{abstract}

Accepted 21 October 2003

\begin{abstract}
Objective: To determine the efficacy of weekly treatment with oral azithromycin for 13 weeks on the severity and resolution of reactive arthritis $(\operatorname{ReA})$.

Methods: 186 patients from 12 countries were enrolled in a randomised, double blind, placebo controlled trial. Inclusion criteria were inflammatory arthritis of $\leqslant 6$ swollen joints, and disease duration of $\leqslant 2$ months. All patients received a single azithromycin dose $(1 \mathrm{~g})$ as conventional treatment for possible Chlamydia infection, and were then randomly allocated to receive weekly azithromycin or placebo. Clinical assessments were made at 4 week intervals for 24 weeks.

Results: 152 patients were analysable (34 failed entry criteria), with a mean (SD) age of 33.8 (9.4) and duration of symptoms 30.7 (17.5) days. Mean $C$ reactive protein (CRP) was $48 \mathrm{mg} / \mathrm{l}$, and $\sim 50 \%$ of those typed were HLA-B27+, suggesting that the inclusion criteria successfully recruited patients with acute $\operatorname{ReA}$. Treatment and placebo groups were well matched for baseline characteristics. There were no statistical differences for changes in any end point (swollen and tender joint count, joint pain, back pain, heel pain, physician and patient global assessments, and CRP) between the active treatment and placebo groups, analysed on an intention to treat basis or according to protocol completion. The time to resolution of arthritis and other symptoms or signs by life table analyses was also not significantly different. Adverse events were generally mild, but were more commonly reported in the azithromycin group.

Conclusions: This large trial has demonstrated that prolonged treatment with azithromycin is ineffective in ReA.
\end{abstract}

R eactive arthritis (ReA) is an inflammatory monarthritis or asymmetric oligoarthritis usually lasting for a few weeks. It is associated with previous infection, mainly of the genitourinary or gastrointestinal tract. ${ }^{1}$ The most frequently identified triggering infections are Chlamydia trachomatis or Ureaplama urealyticum, causing urethritis, and Salmonella, Yersinia, Shigella, or Campylobacter species causing gastroenteritis. These bacteria are obligate or facultative intracellular pathogens. However, in about half of the patients presenting with arthritis suggestive of ReA no triggering infection is found, ${ }^{2}$ although an asymptomatic infection is certainly capable of triggering arthritis. Several lines of evidence suggest that ReA is associated with an immunological response to the above bacteria, characterised by the increased level and prolonged presence of serum antibodies $^{34}$ and of synovial $\mathrm{T}$ cells from affected joints proliferating in vitro to the bacterial antigens. ${ }^{5-7}$ Several observations indicate the presence of Chlamydia trachomatis antigens or related DNA and RNA sequences in synovial samples of patients with ReA. ${ }^{8-11}$ Antigens from Gram negative organisms have also been identified in synovium and synovial fluid, mainly within phagocytic cells, ${ }^{12-14}$ but nucleic acids have been found only rarely. ${ }^{15-17}$ Nevertheless, the weight of evidence clearly suggests that bacterial antigens and/or viable bacteria do reach the affected joints even though the joints are sterile on culture, indicating that any viable bacteria are in a non-cultivable state. Furthermore, bacterial antigens and DNA/RNA have been detected in joints many months after the initial infection, ${ }^{17}$ indicating that persistent infection may be a feature of ReA.

If persistent infection results in the continual delivery of antigens or organisms to joints where they elicit immune responses, this might be the principal pathogenic mechanism responsible for joint inflammation. This in turn raises the hypothesis that antibiotic treatment may be useful in the treatment of ReA, because this would eradicate the organism and allow joint inflammation to settle in the absence of continued antigen production. A placebo controlled study in a limited number of patients suggested that, at least for Chlamydia trachomatis induced arthritis, antibiotics could reduce the duration and severity of established disease. ${ }^{18}$

Azithromycin is an azalide antibiotic which penetrates the cell membranes and concentrates within the lysosomal compartment. Consequently, it is widely distributed throughout the body, achieving higher concentrations in tissues and in a variety of cell types such as phagocytes and fibroblasts than in blood, with a tissue/serum concentration ratio ranging from 50 to 1150 . In animal models, data indicate that delivery of biologically available azithromycin to infected tissue is further enhanced by inflammatory processes. ${ }^{19}{ }^{20}$ In man, the efficacy encompasses the pathogens generally associated with classical ReA-that is, Chlamydia trachomatis, Ureaplasma, Salmonella, Shigella, Yersinia, Campylobacter, while it also has activity against organisms which can be associated with postinfectious arthritis, such as Streptococcus and Gonococcus. In patients with acute Chlamydia trachomatis urogenital infection, a single dose of $1 \mathrm{~g}$ of azithromycin was shown to be as effective as a 7 day course of doxycyline. ${ }^{21} 22$

Abbreviations: CRP, $C$ reactive protein; DMARDs, disease modifying antirheumatic drugs; ITT, intention to treat; LCR, ligase chain reaction; $P C R$, polymerase chain reaction; $R e A$, reactive arthritis 
Table 1 Demographic data and disease characteristics at baseline (mean (SD) for continuous variables, count (\%) for categorical variables)

\begin{tabular}{|c|c|c|c|}
\hline & $\begin{array}{l}\text { Azithromycin } \\
(\mathrm{n}=81)\end{array}$ & $\begin{array}{l}\text { Placebo } \\
(n=71)\end{array}$ & p Value* \\
\hline Age (years) & $33.0(9.8)$ & $34.7(8.9)$ & 0.28 \\
\hline Duration of arthritis (days) & $30.1(17.3)$ & $30.7(17.9)$ & 0.85 \\
\hline Women & $25(31)$ & $24(34)$ & 0.70 \\
\hline Previous similar episode & $17(21)$ & $15(21)$ & 0.92 \\
\hline $\begin{array}{l}\text { Recent intra-articular steroid } \\
\text { injection }\end{array}$ & $20(25)$ & $17(24)$ & 0.98 \\
\hline Heel enthesopathy & $28(35)$ & $30(42)$ & 0.33 \\
\hline Urethritis (symptom) & $13(16)$ & $12(17)$ & 0.86 \\
\hline Diarrhoea (symptom) & $5(6)$ & $2(3)$ & 0.33 \\
\hline Skin abnormalities & $11(14)$ & $10(14)$ & 0.93 \\
\hline Eye abnormalities & $17(21)$ & $14(20)$ & 0.85 \\
\hline Genitourinary abnormalities & $19(24)$ & $17(24)$ & 0.97 \\
\hline HLA-B27† & $22(63)$ & $12(41)$ & 0.09 \\
\hline
\end{tabular}

We therefore chose azithromycin to investigate whether a 3 month course of treatment could hasten recovery or diminish the severity of ReA, or both.

\section{PATIENTS AND METHODS \\ Study design}

The study was a randomised, multicentre, placebo controlled, double blind study of 12 weeks comparing the efficacy of $1 \mathrm{~g}$ oral azithromycin weekly (two tablets of $500 \mathrm{mg}$ ) for 12 weeks versus placebo, starting one week after a $1 \mathrm{~g}$ single dose of azithromycin.

\section{Eligibility}

Patients between 16 and 55 years presenting with an acute unexplained inflammatory arthritis were eligible for the study if the enrolling physician considered the diagnosis of ReA a reasonable possibility-that is, alternative causes of acute arthropathy such as septic arthritis, Lyme disease, crystal arthropathy, and rheumatic fever had been excluded by routine investigations. Patients in whom joint symptoms might be attributed to spondyloarthropathies other than ReA (or undifferentiated spondyloarthropathy), osteoarthritis, rheumatoid arthritis (including those with rheumatoid factor), or systemic lupus erythematosus were also excluded, together with those with trauma or orthopaedic conditions. Enrolment required duration of symptoms of $\leqslant 2$ months and involvement of $\leqslant 6$ single swollen joints. The criteria intentionally did not require preceding gastrointestinal or genitourinary symptoms because these are commonly absent, ${ }^{2}$ and we wished to recruit a clinically representative population of patients with ReA.

Criteria for exclusion included pregnancy and lactation, known hypersensitivity to macrolides or azithromycin, use of ergotamine or digitalis, an estimated creatinine clearance of

Table 2 Reasons for termination of the study (counts (\%))

\begin{tabular}{lcc}
\hline & $\begin{array}{c}\text { Azithromycin } \\
(\mathbf{n}=81)\end{array}$ & $\begin{array}{c}\text { Placebo } \\
(\mathbf{n}=71)\end{array}$ \\
\hline No or insufficient response treatment & $5(6)$ & $4(6)$ \\
Laboratory abnormalities & $1(1)$ & $1(1)$ \\
Adverse events & $3(4)$ & $2(3)$ \\
Patient's request & $3(4)$ & $3(4)$ \\
Investigator's decision & $6(7)$ & $11(15)$ \\
Intra-articular corticosteroid injections & $1(4)$ & $1(1$ \\
Other & $4(5)$ & $1(1)$ \\
Completed study & $57(70)$ & $47(66)$ \\
\hline
\end{tabular}

$<40 \mathrm{ml} / \mathrm{min}$, and serum values of alanine aminotransferase, aspartate aminotransferase, and alkaline phosphatase higher than twice the upper limit. Moreover, patients were excluded for the following conditions:

- Use of antibiotics for 10 days or more within 30 days before enrolment

- Administration of corticosteroids (oral, intravenous, intramuscular) or disease modifying antirheumatic drugs (DMARDs) within 2 months before enrolment

- Intra-articular corticosteroid injection within 2 weeks before enrolment

- Infections requiring antibiotic treatment in addition to the study drug

- History of peptic ulceration, gastrectomy, or any other gastrointestinal condition that might affect absorption of the study drug

- Evidence of drug abuse or alcoholism

- Immunodeficiency from any cause (but known HIV positive patients could be enrolled, provided that they had no evidence of being immunosuppressed).

\section{Informed consent}

The patient had to give written informed consent in accordance with the provisions of the pertinent excerpt from the revised Declaration of Helsinki. Before entry into this study, each potential study participant was informed of the nature, duration, and purpose of the study, the methods and means by which the study drug was to be administered, and all the potential benefits, inconveniences, and hazards that might reasonably be expected.

\section{Study description}

The study was of 6 months' duration, including a 12 week study drug administration period (azithromycin or placebo after $1 \mathrm{~g}$ single dose of azithromycin). To relieve pain and inflammation patients were allowed to take piroxicam $20 \mathrm{mg}$ once a day for as long as was needed. Paracetamol, in addition to piroxicam, was provided for further pain relief. Patients who were intolerant of piroxicam were allowed to change to another non-steroidal anti-inflammatory drug. If oral corticosteroids or DMARDs were required during the study, the patient was removed from the trial at the time these drugs were given.

Intra-articular steroids were avoided where possible; however, if these drugs were required they were permitted only during monthly visits, and only given after evaluations were performed and recorded on the case record form. In cases where injections were given between scheduled visits, the patients were withdrawn from the study.

Visits were scheduled every 4 weeks for 24 weeks.

\section{Assessments}

Outcome measures of disease activity and therapeutic efficacy were obtained at baseline and every 4 weeks for 24 weeks. Outcome measures included a variety of assessments reported by the patient and clinician.

Patient self assessment measures included overall disease activity (five point scale: $1=$ asymptomatic; $2=$ mild; 3 =moderate; $4=$ severe; $5=$ very severe) and pain site assessment (assessment of pain in joints, back, and heels, each on a five point scale)

Clinical assessment measures included the number of swollen joints and the number of tender joints using a 56 joint schema (in which dactylitis is counted as one swollen joint), the presence or absence of enthesopathies at the heel, the overall disease activity according to a five point scale, and 
Table 3 Mean (SD) changes in disease activity measures from baseline to 24 weeks (ITT, last observation carried forward) in the azithromycin and placebo groups

\begin{tabular}{|c|c|c|c|c|c|}
\hline & \multicolumn{2}{|c|}{ Azithromycin ( $n=81)$} & \multicolumn{2}{|c|}{ Placebo $(n=71)$} & \multirow[b]{2}{*}{ Treatment effect† } \\
\hline & Baseline* & Change & Baseline* & Change & \\
\hline Physician global & $2.06(0.71)$ & $1.11(0.86$ to 1.36$)$ & $2.00(0.70)$ & 1.21 (0.98 to 1.44$)$ & $0.10(-0.24$ to 0.44$)$ \\
\hline Patient global & $2.11(0.72)$ & $1.14(0.87$ to 1.41$)$ & $2.06(0.77)$ & $1.18(0.94$ to 1.43$)$ & $0.04(-0.32$ to 0.42$)$ \\
\hline Joint pain & $2.20(0.73)$ & $1.32(1.06$ to 1.59$)$ & $1.99(0.84)$ & $1.23(0.96$ to 1.49$)$ & $-0.09(-0.47$ to 0.30$)$ \\
\hline Back pain & $0.52(0.85)$ & $0.38(0.19$ to 0.57$)$ & $0.38(0.72)$ & 0.21 (0.03 to 0.39$)$ & $-0.17(-0.43$ to 0.09$)$ \\
\hline Heel pain & $0.62(0.98)$ & $0.33(0.12$ to 0.55$)$ & $0.73(1.00)$ & 0.35 (0.09 to 0.61$)$ & $0.02(-0.31$ to 0.35$)$ \\
\hline Swollen joint count & $2.63(1.53)$ & 1.44 (0.95 to 1.94$)$ & $2.25(1.28)$ & 1.44 (1.01 to 1.86$)$ & $-0.01(-0.66$ to 0.64$)$ \\
\hline Tender joint count & $3.69(3.31)$ & $1.79(0.92$ to 2.65$)$ & $3.52(3.45)$ & $1.76(0.87$ to 2.65$)$ & $-0.03(-1.26$ to 1.21$)$ \\
\hline CRP & $43(49)$ & $25(11$ to 38$)$ & $47(55)$ & $35(20$ to 50$)$ & $10.0(-9.6$ to 30.5$)$ \\
\hline CRP centrally measured & $60(51)$ & $47(30$ to 64$)$ & $38(55)$ & 32 (12 to 52$)$ & $-15.0(-40.0$ to 11.0$)$ \\
\hline
\end{tabular}

*No significant difference between baseline values; tmean $(95 \% \mathrm{Cl})$ difference (placebo minus azithromycin) between 24 week changes in disease activity measures.

presence of extra-articular manifestations (conjunctivitis, keratoderma, oral ulcers).

Laboratory evaluations at each visit included CRP, serum alanine aminotransferase, aspartate aminotransferase, alkaline phosphatase, and creatinine; haemoglobin, packed cell volume, white blood cell count with differential, and platelets were also measured. CRP was measured both at each study site and at a central laboratory.

Urine samples were collected at each visit, stored at $-20^{\circ} \mathrm{C}$, and analysed by ligase chain reaction (LCR) for the presence of Chlamydia trachomatis DNA. These tests, together with measurements of CRP, rheumatoid factor, and HLA-B27 status were each performed at a single laboratory.

Patients were screened for adverse drug reactions and intercurrent illnesses at every visit.

\section{Data collection and analyses}

The primary efficacy measures were physician assessment of disease activity, patient assessment of disease activity, number of swollen and number of tender joints, and time
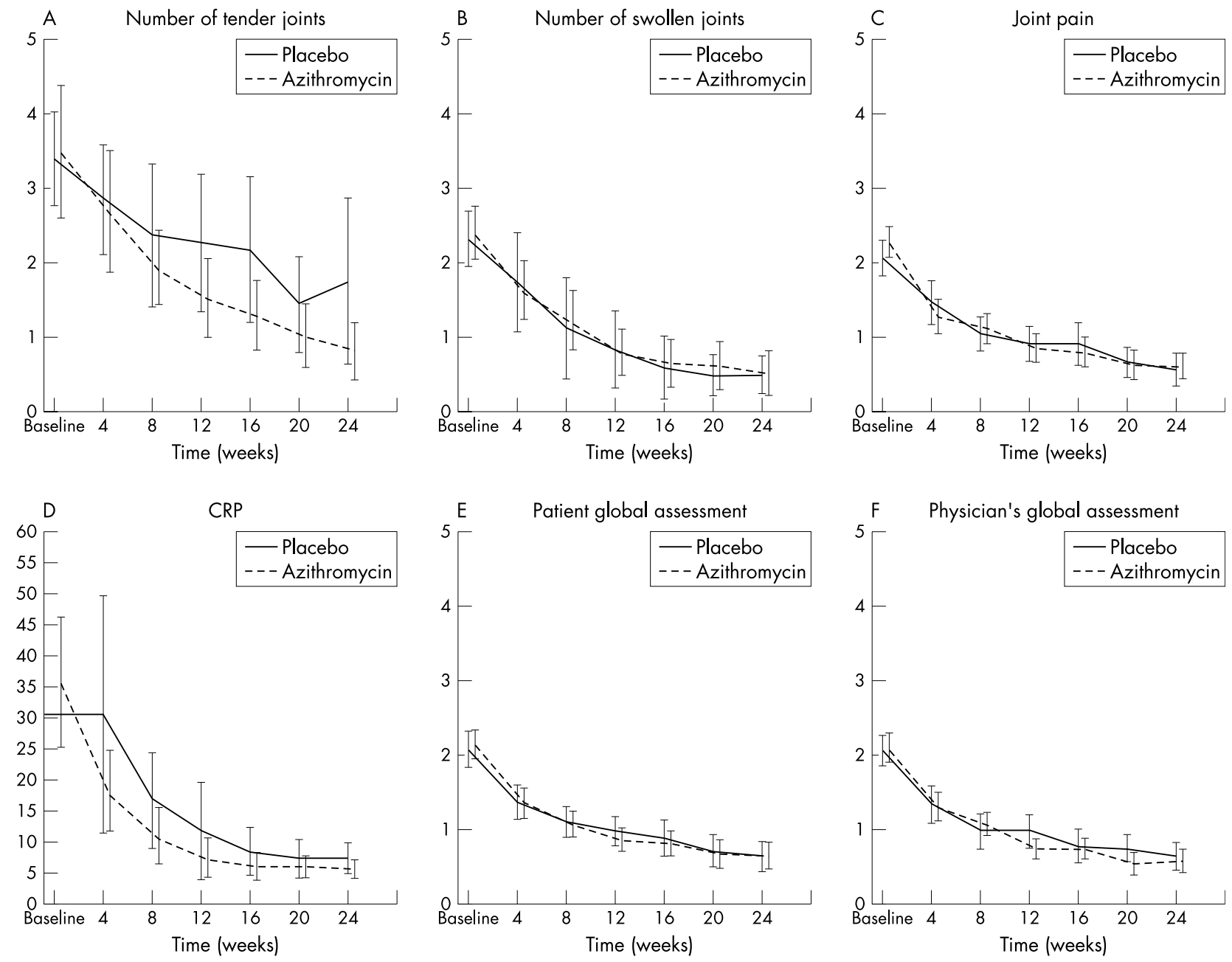

Figure 1 Time dependent improvement of six important end point measures in the completer population (mean (95\% CI)): (A) tender joint count; (B) swollen joint count; (C) joint pain; (D) CRP; (E) patient global assessment; (F) physician's global assessment. 

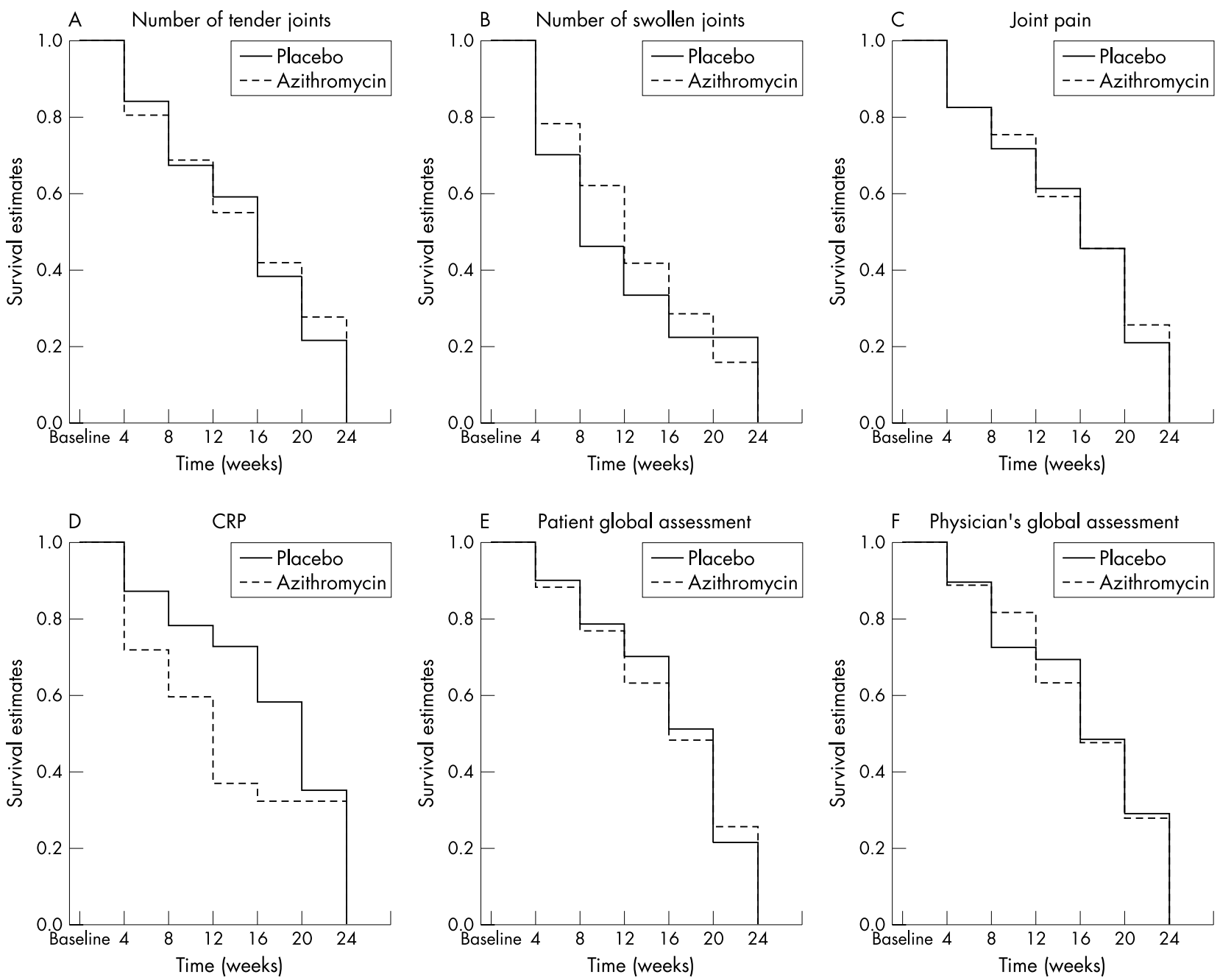

Figure 2 Time to resolution of signs and symptoms (Kaplan-Meier survival analyses). (A) no tender joints; (B) no swollen joints; (C) no joint pain; (D) CRP $<10 \mathrm{mg} / \mathrm{l}$; (E) patient global assessment asymptomatic; (F) physician's global assessment asymptomatic.

to resolution of arthritis, defined as the absence of joint swelling and time to disappearance of pain. Secondary efficacy parameters were the number of patients dropping out from the study owing to lack of efficacy (defined as a patient needing treatment with oral corticosteroids or DMARDs) and changes in other clinical and laboratory measures. The major comparison was between the randomised groups treated with azithromycin or placebo.

Data were collected on appropriate case record forms and entered into the database by one of the authors (P-AP), who

\begin{tabular}{|c|c|c|c|}
\hline & $\begin{array}{l}\text { Azithromycin } \\
\text { ( } \mathrm{n}=81)\end{array}$ & $\begin{array}{l}\text { Placebo } \\
(\mathrm{n}=71)\end{array}$ & p Value* \\
\hline Gastrointestinal & $30(37)$ & $12(17)$ & 0.006 \\
\hline Fungal infections & $2(2)$ & $1(1)$ & 0.64 \\
\hline Respiratory & $10(12)$ & $9(13)$ & 0.95 \\
\hline Cutaneous & $5(6)$ & $3(4)$ & 0.59 \\
\hline Stomatitis & $2(2)$ & $1(1)$ & 0.64 \\
\hline Neurological & $2(2)$ & $1(1)$ & 0.64 \\
\hline Headache & $3(4)$ & 0 & 0.10 \\
\hline Urogenital & 1 (1) & $2(3)$ & 0.48 \\
\hline Laboratory abnormalities & $1(1)$ & $3(4)$ & 0.25 \\
\hline Miscellaneous & $13(16)$ & $10(14)$ & 0.60 \\
\hline
\end{tabular}

also performed the clarification of the data files (collection of missing data from investigators; correction of incorrect data and inconsistencies). Patients not fulfilling the inclusion and exclusion criteria were excluded from the analyses. Data were analysed in the patient population receiving at least one dose of the trial drug (intention to treat (ITT)) and in those completing the entire 24 week study period (completer population). For the ITT analyses the last observation was projected forward to the subsequent missing measurement points.

Summary statistics were used for presentation of demographic and disease variables (mean or median for continuous variables, and counts (percentages) for categorical variables). Efficacy was analysed by comparing the azithromycin and placebo groups in three different ways: $t$ tests for changes from baseline to the end of the study, and repeated measurements analysis of variance for time dependent changes during the study. Kaplan-Meier survival analyses and log rank tests were used to analyse the time to resolution of arthritis and other end points.

\section{RESULTS}

The number of patients originally enrolled was 186, but 34 were excluded for the following reasons: no swollen joint at baseline $(n=5)$, swollen joint count $>6(n=11)$, not fulfilling all inclusion criteria $(n=1)$, one or more exclusion 
criteria present $(n=3)$, duration of symptoms $\geqslant 60$ days $(\mathrm{n}=10)$, missing information on swollen joint count or duration of symptoms $(n=4)$, positive rheumatoid factor test $(\mathrm{n}=3)$ (some patients had more than one reason for being excluded).

The mean (SD) age of the 152 patients fulfilling the inclusion and exclusion criteria was 33.8 (9.4) years, disease duration was 30.4 (17.5) days, and 49 (32\%) were female. The patients were recruited from 12 different European countries (Austria $(n=6)$, Bulgaria $(n=13)$, Denmark $(n=15)$, Finland $(n=26)$, France $(n=17)$, Germany $(\mathrm{n}=8)$, Hungary $(\mathrm{n}=1)$, Lithuania $(\mathrm{n}=25)$, Norway $(n=15)$, Slovakia $(n=3)$, The Netherlands $(n=9)$, and United Kingdom $(\mathrm{n}=14)$ ).

The demographic variables and disease characteristics at baseline of the azithromycin and placebo groups were comparable (table 1$)$. Fifty seven $(70 \%)$ of the azithromycin group and $47(66 \%)$ of the placebo group completed the 24 weeks of the trial. No major differences in the reasons for withdrawal were seen between the treatment groups (table 2).

Improvement was seen in both the azithromycin and placebo groups, with favourable changes across all measures of disease activity. However, the changes were of similar magnitude, and statistically significant differences were not observed for any end point in the ITT population (table 3 ). Similar results were obtained in the completer population (data not shown).

The improvement was seen early after randomisation. Figures 1A-F show the mean scores for six important end points (tender and swollen joint count, joint pain, CRP, and patient and physician global assessments) in the completer population. The time dependent improvement was similar for both treatment groups and no differences were seen when the groups were compared statistically by repeated measurements analysis of variance. Similar results were seen in the ITT population (data not shown).

Time to resolution of arthritis (no joint tenderness, no joint swelling), to resolution of joint pain, to achieving CRP $<10$ $\mathrm{mg} / \mathrm{l}$, and to zero activity on the patient and physician global assessments were compared by life table analyses (figs 2AF). No differences were found between the treatment groups for the time to achieve these treatment successes-both in the ITT (figs 2A-F) and completer population (data not shown).

Adverse events were more frequently reported in the azithromycin group than in the placebo group (table 4). The numbers of patients reporting adverse events during the first 4 weeks were 30 in the azithromycin and 13 in the placebo groups $(p=0.01), 25$ versus 9 during the subsequent 4 week period $(p=0.01)$, and 18 versus 7 during the last 4 weeks receiving active drug treatment $(p=0.07)$. No differences in reported adverse events were seen during the observation period. Adverse events were generally mild and did not lead to any group difference in withdrawal rate (table 2). Adverse events in the azithromycin group were most frequently reported from the gastrointestinal system (table 4).

It was initially planned to analyse data from patients positive for infection with Chlamydia. However, Chlamydia infection was only detected in 12/130 patients in whom urine was tested by LCR. All these patients were LCR negative after treatment, indicating that administration of the single dose of azithromycin was effective in those who otherwise received placebo. This cohort was too small for assessment of clinical outcome.

\section{DISCUSSION}

There have been several trials of prolonged antibiotic treatment in the treatment of ReA. ${ }^{18}{ }^{23-26}$ Most of these have shown that antibiotics have no beneficial effect; a notable exception is the trial by Lauhio et al, in which treatment with lymecycline decreased the duration of ReA due to Chlamydia infection. ${ }^{18}$ However, this finding arose out of a subgroup analysis of the cohort of patients recruited to the study and the trial included somewhat smaller numbers. Effective treatment with antibiotics for chronic yersiniosis has also been reported, ${ }^{27}{ }^{28}$ but many of these patients had other disease manifestations such as lymphadenopathy rather than classical ReA. The most convincing evidence for the effectiveness of antibiotic in ReA comes from the study of Bardin et al in Greenland, ${ }^{29}$ but in that study antibiotics were not used to hasten resolution of arthritis, but prophylactically to decrease the incidence of sexually acquired infection in a population predisposed to develop ReA. A recent report also suggested that patients treated with ciprofloxacin for Salmonella gastroenteritis had a diminished risk of developing ReA or other musculoskeletal complications. ${ }^{30}$ Additionally, a follow up analysis of an originally negative placebo controlled trial on the efficacy of ciprofloxacin in acute reactive arthritis $^{26}$ indicated that a 3 month course with antibiotics in the acute phase might have a beneficial effect on the long term prognosis. ${ }^{31}$

Previous trials have adopted different recruitment policies, with some restricted to disease of short duration and others including those with chronic disease. In addition the evidence required to make a diagnosis of ReA also varies in different studies. In the absence of agreed classification criteria for ReA, ${ }^{32}$ selection of the patients for inclusion in clinical trials presents significant problems. If positive culture of the triggering organism is demanded for inclusion many cases of ReA will be excluded, and there would be significant difficulty in accumulating large numbers of these patients in a short time. Likewise insistence on preceding gastrointestinal or genitourinary symptoms excludes some patients with undoubted ReA. ${ }^{2}$ The policy of the current trial was to recruit patients with acute disease ( $\leqslant 2$ months), and $\leqslant 6$ swollen joints. This six joint cut off point was chosen as an expert decision. Although ReA may be polyarticular, this is relatively unusual and the upper limit of six affected joints made it less likely that patients with early rheumatoid arthritis would be included. Further, serum samples were reanalysed after the study for presence of rheumatoid factor, which led to the exclusion of three patients. Within ReA and related diseases it has been widely accepted that patients can be classified according to their clinical presentation-for example, as spondyloarthropathy. Actually, the patients in this study also fulfilled the European Spondylarthropathy Study Group criteria for spondyloarthropathy. ${ }^{33}$ Thus, an alternative to the term ReA in this study might be undifferentiated acute spondyloarthropathy.

One limitation of the present study is the lack of comprehensive examinations for triggering infections. The design made it impossible to establish identical routines in all centres and countries for microbiological examinations. Further, it was not possible to perform uniform examinations of antibodies to triggering infections or $\mathrm{T}$ cell proliferation tests. Twenty five synovial fluids were available for examination, but none was positive either by Chlamydia trachomatisspecific amplification using the Abbott LCR assay or by broad range polymerase chain reaction (PCR $)^{34}$ which, however, is less sensitive than species-specific PCR. ${ }^{35}$ Our best approach to explore the microbiological background was to examine urine with LCR, but Chlamydia infection was only detected in $12 / 130$ patients in whom urine was tested. Thus, the results of this study must be interpreted under the understanding that recruitment was designed to reflect the "real world" experience of diagnosis of ReA, where patients who present with acute oligoarticular arthritis for which no other 
explanation such as sepsis or crystal arthritis is forthcoming are likely to have ReA. This strategy seems to have been successful, judging by the proportion of B27+ subjects in the study.

B27+ subjects have been shown to have more severe ReA than B27- subjects $^{36}$ and thus more likely to present to rheumatologists within 8 weeks of the onset of disease. ${ }^{37}$ However, analysis of the B27+ subjects as a separate subset also failed to show the efficacy of antibiotics, although the power of this analysis is evidently limited. The whole study was originally powered to detect an effect of azithromycin similar to that noted for lymecycline in Chlamydia induced ReA. The proportion of patients with evidence of preceding Chlamydia infection shown by PCR of urine was rather low, and no conclusion can be derived from analysis of this subgroup. In this sense the trial does not necessarily negate the previous finding of Lauhio et al, ${ }^{18}$ but no other study has positively supported its conclusions.

Several recent trials have tested ciprofloxacin; this is the first to use azithromycin. The drug was used because it has excellent activity against ReA associated organisms (particularly Chlamydiae) and achieves high intracellular concentrations-this may be important in ReA, which involves species which are obligate or facultative intracellular organisms. Lastly, its once weekly dosage lends itself particularly well to prolonged administration. The drug was well tolerated with few withdrawals due to adverse effects, although the number of adverse events was considerably higher than in the placebo group. One important consideration for the trial was the danger of leaving Chlamydia infected patients untreated if they were allocated to placebo treatment. For this reason all patients received a single dose of azithromycin at entry, because this is recognised as appropriate treatment for genital tract Chlamydia infection, and there is no evidence to suggest that short term treatment with antibiotics has any influence on the course of ReA.

If the results in this trial (and other recent trials of the same general kind) are valid, what are the implications for our understanding of the pathogenesis of ReA? It might be argued that arthritis is not maintained by persistent infection, and that the bacterial nucleic acids and antigens repeatedly demonstrated in synovial fluid or synovium are not relevant to pathogenesis. ${ }^{8}{ }^{12-14} 1^{38-41}$ Instead infection would be seen as a trigger of some form of autoimmune disease, directed against unknown joint components or even (in B27+ cases) HLA-B27 itself. ${ }^{42}$ However, it is also possible that persistent infection does play a crucial part in pathogenesis, but that the organisms triggering ReA enter a state in which they have low susceptibility to antibiotics, perhaps owing to very slow rates of multiplication. Experimental evidence in Yersinia infection in rats suggests that antibiotics given at any time, except immediately after infection, prolong organism survival and excretion. ${ }^{43}$

In summary, this study does not support the use of a prolonged course of antibiotics for the alleviation of ReA. This is an important conclusion, because such treatment has become commonplace, perhaps as a reasonable response to the demonstration of organisms in the ReA joint. Instead disease modifying drugs such as sulfasalazine ${ }^{44-46}$ and, possibly, methotrexate may be justified in severe disease which fails to resolve spontaneously, and there are now also reports of efficacy of tumour necrosis factor blocking compounds in chronic ReA. ${ }^{47} 48$

\section{ACKNOWLEDGEMENTS}

This study was supported by a research grant from Pfizer to EULAR. Pfizer also provided some logistical support for meetings and data management. The authors thank all the investigators who contributed to this study: Drs Bourgeois, Dehais, Kahn, and Valat, France; Drs Angelskaar and Helgetveit, Norway; Drs Pileckyte,
Ranceva, and Venalis, Lithuania; Drs Dawes and Swinson, United Kingdom; Drs Häntzschel and Wollenhaupt, Germany; Drs Ebner and Machold, Austria; Dr Korda, Hungary; Drs Hakala, KaipiainenSeppänen, Luukkainen, Nissilä, Paimela, and Yli-Kerttula, Finland; Dr Mateicka, Slovakia; Drs Daugaard, Ejstrup, Lindberg, Nielsen, and van Overeem Hansen, Denmark; and Dr Baudoin, The Netherlands.

\section{Authors' affiliations}

T K Kvien, P Mowinckel, Department of Rheumatology, Diakonhiemmet Hospital, Oslo, Norway

J S H Gaston, University of Cambridge, Cambridge, UK

T Bardin, Hôpital Lariboisiere, Paris, France

I Butrimiene, Vilnius University, Institute of Experimental and Clinical Medicine, Vilnius, Lithuania

B A C Dijkmans, VU Medical Centre, Amsterdam, The Netherlands M Leirisalo-Repo, Helsinki University Central Hospital, Helsinki, Finland P Solakov, University Clinic of Rheumatology, Plovdiv, Bulgaria

M Altwegg, University of Zurich, Zurich, Switzerland

P-A Plan, Othon 2A, Grandson, Switzerland

T Vischer, Hôpital Cantonal Universitaire, Geneva, Switzerland

\section{REFERENCES}

1 Keat A. Reiter's syndrome and reactive arthritis in perspective. N Engl J Med 1983;309:1606-15

2 Kvien TK, Glennas A, Melby K, Granfors K, Andrup O, Karstensen B, et al. Reactive arthritis: incidence, triggering agents and clinical presentation. J Rheumatol 1994;21:115-22.

3 Granfors K, Viljanen M, Tiilikainen A, Toivanen A. Persistence of $\lg M$, lgG and $\lg A$ antibodies to Yersinia in yersinia arthritis. $J$ Infect Dis 1980;141:424-9.

4 Granfors K, Toivanen A. IgA-anti-yersinia antibodies in yersinia triggered reactive arthritis. Ann Rheum Dis 1986;45:561-5.

5 Gaston JS, Life PF, Granfors K, Merilahti-Palo R, Bailey L, Consalvey S, et al. Synovial T lymphocyte recognition of organisms that trigger reactive arthritis. Clin Exp Immunol 1989;76:348-53.

6 Sieper J, Braun J, Wu P, Kingsley G. T cells are responsible for the enhanced synovial cellular immune response to triggering antigen in reactive arthritis. Clin Exp Immunol 1993;91:96-102.

7 Hermann E, Yu DT, Meyer zum Buschenfelde KH, Fleischer B. HLA-B27restricted CD8 T cells derived from synovial fluids of patients with reactive arthritis and ankylosing spondylitis. Lancet 1993;342:646-50.

8 Gerard HC, Branigan PJ, Schumacher HR Jr, Hudson AP. Synovial Chlamydia trachomatis in patients with reactive arthritis/Reiter's syndrome are viable but show aberrant gene expression. J Rheumatol 1998;25:734-42.

9 Freise J, Gerard HC, Bunke T, Whittum-Hudson JA, Zeidler H, Kohler L, et al. Optimised sample DNA preparation for detection of Chlamydia trachomatis in synovial tissue by polymerase chain reaction and ligase chain reaction. Ann Rheum Dis 2001;60:140-5.

10 Schnarr S, Putschky N, Jendro MC, Zeidler H, Hammer M, Kuipers JG, et al. Chlamydia and Borrelia DNA in synovial fluid of patients with early undifferentiated oligoarthritis: results of a prospective study. Arthritis Rheum 2001;44:2679-85.

11 Keat A, Thomas B, Dixey J, Osborn M, Sonnex C, Taylor-Robinson D. Chlamydia trachomatis and reactive arthritis: the missing link. Lancet 1987; i:72-4

12 Granfors K, Jalkanen S, von Essen R, Lahesmaa-Rantala R, Isomaki O, Pekkola-Heino K, et al. Yersinia antigens in synovial-fluid cells from patients with reactive arthritis. N Engl J Med 1989;320:216-21.

13 Granfors K, Jalkanen S, Lindberg AA, Maki-lkola O, von Essen R, LahesmaaRantala $R$, et al. Salmonella lipopolysaccharide in synovial cells from patients with reactive arthritis. Lancet 1990;335:685-8.

14 Granfors K, Jalkanen S, Toivanen P, Koski J, Lindberg AA. Bacterial lipopolysaccharide in synovial fluid cells in Shigella triggered reactive arthritis. J Rheumatol 1992;19:500.

15 Nikkari S, Merilahti-Palo R, Saario R, Soderstrom KO, Granfors K, Skurnik M, et al. Yersinia-triggered reactive arthritis. Use of polymerase chain reaction and immunocytochemical staining in the detection of bacterial components from synovial specimens. Arthritis Rheum 1992;35:682-7.

16 Nikkari S, Rantakokko K, Ekman P, Mottonen T, Leirisalo-Repo M, Virtala M, et al. Salmonella-triggered reactive arthritis: use of polymerase chain reaction, immunocytochemical staining, and gas chromatography-mass spectrometry in the detection of bacterial components from synovial fluid. Arthritis Rheum 1999;42:84-9

17 Gaston JS, Cox C, Granfors K. Clinical and experimental evidence for persistent Yersinia infection in reactive arthritis. Arthritis Rheum 1999;42:2239-42.

18 Lauhio A, Leirisalo-Repo M, Lahdevirta J, Saikku P, Repo H. Double-blind, placebo-controlled study of three-month treatment with lymecycline in reactive arthritis, with special reference to Chlamydia arthritis. Arthritis Rheum 1991;34:6-14.

19 Neu HC. Clinical microbiology of azithromycin. Am J Med 1991;91:12-18S.

20 Schentag JJ, Ballow CH. Tissue-directed pharmacokinetics. Am J Med 1991;91:5-11S.

21 Lauharanta J, Saarinen K, Mustonen MT, Happonen HP. Single-dose oral azithromycin versus seven-day doxycycline in the treatment of 
non-gonococcal urethritis in males. J Antimicrob Chemother 1993;31(suppl E):177-83.

22 Lister PJ, Balechandran T, Ridgway GL, Robinson AJ. Comparison of azithromycin and doxycycline in the treatment of non-gonococcal urethritis in men. J Antimicrob Chemother 1993;31(suppl E): 185-92.

23 Toivanen A, Yli-Kerttula T, Luukkainen R, Merilahti-Palo R, Granfors K, Seppala J. Effect of antimicrobial treatment on chronic reactive arthritis. Clin Exp Rheumatol 1993;11:301-7.

24 Wakefield D, McCluskey P, Verma M, Aziz K, Gatus B, Carr G. Ciprofloxacin treatment does not influence course or relapse rate of reactive arthritis and anterior uveitis. Arthritis Rheum 1999;42:1894-7.

25 Sieper J, Fendler C, Laitko S, Sorensen H, Gripenberg-Lerche C, Hiepe F, et al. No benefit of long-term ciprofloxacin treatment in patients with reactive arthritis and undifferentiated oligoarthritis: a three-month, multicenter, doubleblind, randomized, placebo-controlled study. Arthritis Rheum 1999;42:1386-96.

26 Yli-Kerttula T, Luukkainen R, Yli-Kerttula U, Mottonen T, Hakola M, Korpela M, et al. Effect of a three month course of ciprofloxacin on the outcome of reactive arthritis. Ann Rheum Dis 2000;59:565-70.

27 Hoogkamp-Korstanje JA, de Koning J, Heesemann J. Persistence of Yersinia enterocolitica in man. Infection 1988;16:81-5.

28 Hoogkamp-Korstanje JA, Moesker H, Bruyn GA. Ciprofloxacin v placebo for treatment of Yersinia enterocolitica triggered reactive arthritis. Ann Rheum Dis 2000:59:914-17.

29 Bardin T, Enel C, Cornelis F, Salski C, Jorgensen C, Ward R, et al. Antibiotic treatment of venereal disease and Reiter's syndrome in a Greenland population. Arthritis Rheum 1992;35:190-4.

30 Hannu T, Mattila L, Siitonen A, Leirisalo-Repo M. Reactive arthritis following an outbreak of Salmonella typhimurium phage type 193 infection. Ann Rheum Dis 2002;61:264-6

31 Yli-Kerttula T, Luukkainen R, Yli-Kerttula U, Mottonen T, Hakola M, Korpela M et al. Effect of a three month course of ciprofloxacin on the late prognosis of reactive arthritis. Ann Rheum Dis 2003:62:880-4.

32 Braun J, Kingsley G, van der Heijde D, Sieper J. On the difficulties of establishing a consensus on the definition of and diagnostic investigations for reactive arthritis. Results and discussion of a questionnaire prepared for the 4th International Workshop on Reactive Arthritis, Berlin, Germany, July 3-6, 1999. J Rheumatol 2000;27:2185-92.

33 Dougados M, van der Linden S, Juhlin R, Huiffeldt B, Amor B, Calin A, et al The European Spondylarthropathy Study Group preliminary criteria for the classification of spondylarthropathy. Arthritis Rheum 1991;34:1218-27.

34 Goldenberger D, Kunzli A, Vogt $P$, Zbinden R, Altwegg M. Molecular diagnosis of bacterial endocarditis by broad-range PCR amplification and direct sequencing. J Clin Microbiol 1997;35:2733-9.
35 Lipowsky C, Altwegg M, Michel BA, Bruhlmann P. Detection of Borrelia burgdorferi by species-specific and broad-range PCR of synovial fluid and synovial tissue of Lyme arthritis patients before and after antibiotic treatment. Clin Exp Rheumatol 2003;21:271-2.

36 Leirisalo M, Skylv G, Kousa M, Voipio-Pulkki LM, Suoranta H, Nissila M, et al. Followup study on patients with Reiter's disease and reactive arthritis, with special reference to HLA-B27. Arthritis Rheum 1982;25:249-59.

37 Ekman P, Kirveskari J, Granfors K. Modification of disease outcome in Salmonella-infected patients by HLA-B27. Arthritis Rheum 2000:43:1527-34.

38 Hammer M, Zeidler H, Klimsa S, Heesemann J. Yersinia enterocolitica in the synovial membrane of patients with Yersinia-induced arthritis. Arthritis Rheum 1990;33:1795-800

39 Merilahti-Palo R, Soderstrom KO, Lahesmaa-Rantala R, Granfors K Toivanen A. Bacterial antigens in synovial biopsy specimens in yersinia triggered reactive arthritis. Ann Rheum Dis 1991;50:87-90.

40 Granfors K, Merilahti-Palo R, Luukkainen R, Mottonen T, Lahesmaa R, Probst $P$, et al. Persistence of Yersinia antigens in peripheral blood cells from patients with Yersinia enterocolitica O:3 infection with or without reactive arthritis. Arthritis Rheum 1998:41:855-62.

41 Kuipers JG, Nieffeld L, Dreses-Werringloer U, Koehler L, Wollenhaupt J, Zeidler $\mathrm{H}$, et al. Optimised sample preparation of synovial fluid for detection of Chlamydia trachomatis DNA by polymerase chain reaction. Ann Rheum Dis 1999:58:103-8.

42 Boyle LH, Goodall JC, Opat SS, Gaston JS. The recognition of HLA-B27 by human CD4(+) T lymphocytes. J Immunol 2001;167:2619-24.

43 Zhang Y, Gripenberg-Lerche C, Soderstrom KO, Toivanen A, Toivanen P. Antibiotic prophylaxis and treatment of reactive arthritis. Lessons from an animal model. Arthritis Rheum 1996;39:1238-43.

44 Dougados $M$, van der Linden S, Leirisalo-Repo M, Huiffeldt B, Juhlin R, Veys E, et al. Sulfasalazine in the treatment of spondylarthropathy. A randomized, multicenter, double-blind, placebo-controlled study. Arthritis Rheum 1995; 38:618-27.

45 Egsmose C, Hansen TM, Andersen LS, Beier JM, Christensen L, Ejstrup L, et al. Limited effect of sulphasalazine treatment in reactive arthritis. A randomised double blind placebo controlled trial. Ann Rheum Dis 1997;56:32-6.

46 Clegg DO, Reda DJ, Weisman MH, Cush JJ, Vasey FB, Schumacher HR Jr, et al. Comparison of sulfasalazine and placebo in the treatment of reactive arthritis (Reiter's syndrome). A Department of Veterans Affairs Cooperative Study. Arthritis Rheum 1996;39:2021-7.

47 Brandt J, Haibel H, Reddig J, Sieper J, Braun J. Successful short term treatment of severe undifferentiated spondyloarthropathy with the anti-tumor necrosis factor-alpha monoclonal antibody infliximab. J Rheumatol 2002;29:118-22.

48 Kaipiainen-Seppänen O, Niinisalo H, Korpilähde T, Virolainen J. Treatment of reactive arthritis with infliximab. Scand J Rheumatol 2003;32:122-4. 